\title{
تحليل صيغ الفعل وأزمانه في اللغة العربية
}

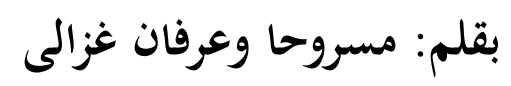

جامعة شيخ نور جاتى الإسلامية الحكومية شربون

ملخص الإن

وهذا البحث من البحث الوصفي بالمدخل الكيفي وطريقة البحث الكيفي الوصفي.

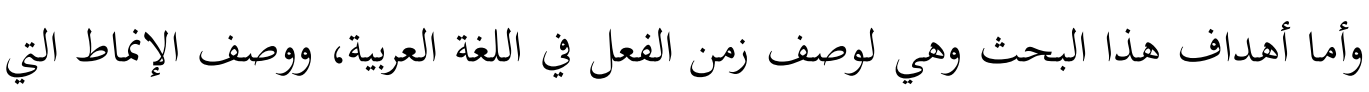

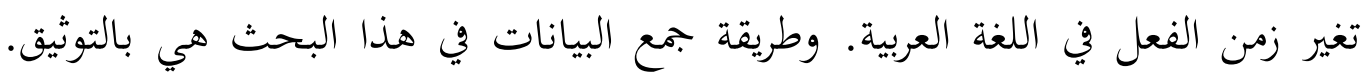

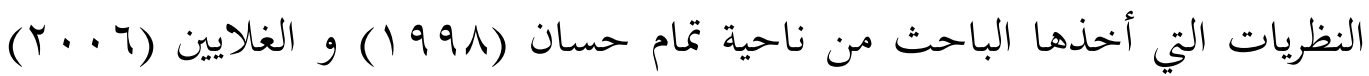

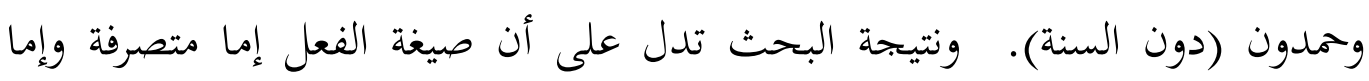

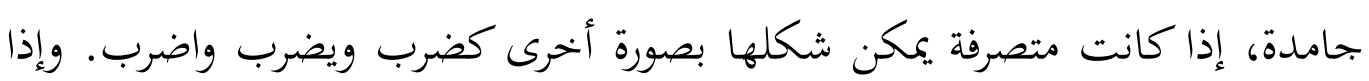
كانت جامدة فعليها صورة واحدة كصه، و حيهل, وعسى، وغيره من الأفعال

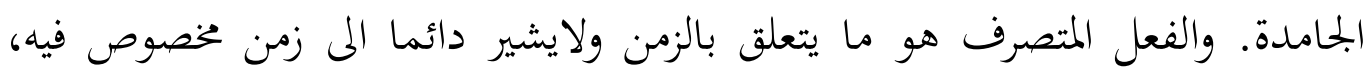
فالفعل الماضي قد يشير الى الزمن المستقبلي والفعل المضارع قد يشير الى الزمن الماضي.

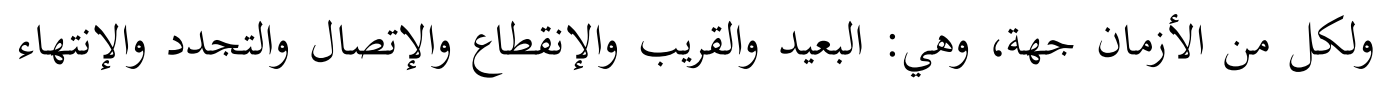
والإستمرار والمقاربة والشروع والعادة والبساطة.

الكلمة الرئيسية: الفعل، صيغ الفعل، أزمان، جهة، اللغة العربية.

المقدمة

لكل لغة نظام فرعي منها مورفوسينتاك (Morphosintax). هي وصدة بين

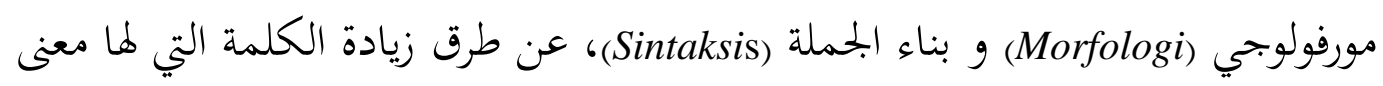

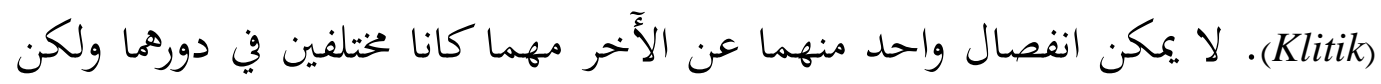


هما أصبحا واضحين لبحث الاحد منهما لا يمكن أن ينفصل عن الآخر فبذالك 'Morphosintax) ' نشأت مورفوسينتاك

في جميع اللغات نظام الفعل، ويطلق عليه الزمن و الجانب والعمل, هذا النظام يشمل مورفولوجي فقط' . وللفعل ثلاث صيغ صيغة ماضي ومضارع وأمر. وله في السياق وظيفة ككونه مسنادا، فإذا هو مقترن بالزمن. ولكن في الحقيقة كثير من الفعل الذي كونه مسنادا إليه كما في "أن تصوم خير لكم"، فهو غير مقترن بالزمن. الزمن هو المعلومات في الجملة التي تدل فيها وقت العمل والحدث والإجراء أو

الخبرات المذكورة في الفعل. وورد الزمن عادة يدل لوقت الماضي والحال والاستقبال؛ . إن لكثير من اللغات ما يدل على الزمن الحالي والزمن الماضي والزمن المستقبل • اللغة الإندونيسية لم تتم إضاعة الوقت بالصرف (مورفولوجي) ولكن اضاعتها بالنحو (المعجمي) أي باللفظ "السابق (Lampau) للوقت الماضي، والان (Kini) للوقت الحالي، والأتي (Akan Datang) للوقت المستقبلي". كما في المثال التالي:

- $\quad$ Pak Lurah Itu Sudah Mandi

- $\quad$ Pak Lurah Itu Sedang Mandi

- $\quad$ Pak Lurah Itu Akan Mandi

ويتصف الزمن في اللغة العربية بالصرف (مورفولوجي)، وفيها يضمن الزمن في الفعل الذي ينقسم الى ثلاثة اقسام وهي الفعل الماضي والفعل المضارع والفعل الامر ·.

${ }^{1}$.Abdul Chaer,. Linguistik Umum. (Jakarta: Rineka Cipta, 2012) Hal. 206

${ }^{2}$ Verhaar, J. W. Asas-asas Linguitik Umum (Yogyakarta: Gadjah Mada University Press, 2010) Hal. 239.

${ }^{3}$ Alghulayaini . Jami’u al-Durus (Beirut: Daru al-Fikri. 2006) Hal. 31

${ }^{4}$ Loc.cit.

${ }^{5}$ Verhaar, J. W. Asas-asas Linguitik Umum (Yogyakarta: Gadjah Mada University Press, 2010) Hal. 239.

${ }^{6}$ Abdul Majid. Dilalatu al-Zaman Fi al-Arobiyati (Daru at-Tebqol LI an-Nasyar) Hal. 22. 
كما في العديد من اللغات الأخرى ينقسم الزمن إلى ثلاثة، وهي الماضي والحاضر

والمستقبل، فأما الحاضر والمستقبل فيدل عليهما الفعل المضارع و الماضي يدل عليه فعل الماضي.

بشكل عام كل الفعل لا يدل على الحدث و الزمن التي تقوم على وقت حدوثها

فقط ولكن بسبب عنصر ما قد انتهى بالفعل و لم ينته به أو لا يزال يحدث كما في اللفظ "الله عز وجل" هذا لا يوصف على الأحداث أو الظروف في الماضي لان صفة العزيز والجليل لله عز و جل قد كان منذ الأزل حتى في أي وقت. وهذا هو لم يتعلق

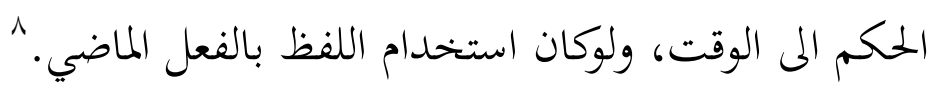
وأما في اللفظ "المدير يلقي الخطبة" فيكون شكل الفعل في هذا المثال هي الفعل المضارع، ولكن إذا درست بعمق أكثر، شكل الفعل فيها تفيد على الحدث الذي يحدث خحلال خطاب.

إن الفعل الماضي لا يشير دائما في الماضي، والفعل المضارع لا يشير دائما في الحاضر أو المستقبل. كما في أية القرأن "اذا جاء نصر الله" (الفتح: ) في هذه الآية الفعل الماضي يعني جاء التي يوجد فيها الزمن القادم، في حين أن القانون الأصلي للفعل الماضي يجب عليه أن يدل الزمن الماضي، و اتضح أن هناك عوامل أخرى التي تغير الزمن للفعل الماضي وهي لفظ"إذا" التي قبل دخوها في الفعل الماضي هو يدل الزمن الماضي تم تغير الزمن بسبب دخولها فيه. ' ' وكذالك الفعل المضارع كما في هذه الأية "ألم تعلم أن الله يعلم ما في السماء والأرض" (الحج: •V) في هذه الآية هناك فعل فئل المضارع "تعلم" والزمن فيها الماضي في حين أن الأصل القانوبي للفعل المضارع ينبغي

${ }^{7}$ Ahmad al-Baijuri. Fathu Robbi al-Baaria (Surabaya: Daru al-Ilmi). Hal 24.

${ }^{8}$ Mardiyah. Verba Perfektum dan Verba Imperfektum 2014 (Indonesia, al-Azhar Seri Humaniora). Hal 204.

${ }^{9}$ Ibid

${ }^{10}$ Ahmad Ibnu Muhammad al-Showi Almaliki, Hasyiyah al-Showi 2007 (Beirut: Daru alFikri) Hal 412. 
عليه أن تدل الزمن الحاضر أو المستقبل ولكن هناك عوامل أخرى التي تغير الزمن للفعل المضارع وهي لفظ "ألم" التي قبل دخوها في الفعل المضارع هو يدل الزمن الحاضر أو المستقبل ثم تغير الزمن بسبب دخولها فيه. اهتم الباحث هذه المشكلة للمساعدة في فهم أعمق للطلاب من أجل بحنب المفاهيم الخاطئة التي تسبب ضرر القاعدة، ومن هنا جاءت الحاجة إلى دراسة معمقة. وبالتالي أهتم أي الباحث في إجراء البحوث على " تحليل صيغ الفعل وأزمانه في اللغة

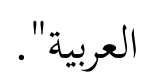
المنهج

المقاربة يستعملها الباحث الوصفي النوعي وهي أن يوصف ويشرح أشكال الفعل وأزمان الفعل والعوامل التي تغير زمان الفعل. من وجه النوعي ينبغي أن تتم المعلومات التي يجمعها الباحث أي من التمهيدي والفرعي. ونوع البحث يستعمله الباحث دراسة المراجع وهو العمل يتعلق بطريقة جميع

$$
\begin{aligned}
& \text { البيانات المراجعي والقراءة والتسجيل وهج معلومات البحث. با } \\
& \text { تحليل صياغ الفعل في اللغة العربية }
\end{aligned}
$$

أن كل لغة لما خصائص مختلفة في صياغ فعلها. وفي اللغة العربية تسمى تشكيل الفعل على التصريفي أو عملية تغيير الصيغة الأصلية لصياغ أخرى لتحقيق معنى المطلوب، فتشكيل الفعل في العربية عادة ما تتألف من ما لا يقل عن ثلاثة أحرف ولها التعريف. في كل من هذه العمليات سوف تنتج صياغا مختلفة من مفردات التي كتبها كلمة، مثل عمليتها للفعل الماضي الى الفعل المضارع والفعل الأمر والفاعل والمفعول. فبذالك يمكن أن بجعل كلا من صياغ الأفعال صيغة للفعل الأخر، هو يسمى بالفعل المتصرف. الفعل من حيث أداءه معنى لايتعلق بزمان أو يتعلق به قسمان هما جامد

${ }^{11}$ Ibid. Hal 113.

12 Muhammad Zed, Metode Penelitian Kepustakaan 2004 (Jakarta: Yayasan Obor Indonesia) Hal. 12 
ومتصرف ب'. فأماالمتصرف فقد سبق بيانه، وأما الفعل الجامد فهو ما أشبه الحرف من حيث أداءه معنى مجردا عن الزمان والحدث المعتبرين في الأفعال فلزم مثله طريقة واحدة في التعبير \& '. فتفصيل بيانه كما التالي:

من الجانب التصريفي، لكل صيغة دور مختلف كما أن دور الفعل مسند والإسم مسند إليه. وفي الواقع يوجد الفعل يقوم مقام الإسم، كالمبتدء من فعل ماضي أومضارع بسبب دخول أن فيه.

\section{1 الفعل الملازم بصيغة واحدة}

هو يسمى بالفعل الجامد لأنه لا يقبل التحول من صورة إلى صورة، بل يلزم صورة واحدة لا يزايلها، وذالك إما كان مخصوصا بصيغة الماضي وإما مخصوصا بصيغة المضارع وإما مخصوصا بصيغة الأمر. أ. الفعل المالازم بصيغة الماضي

هو كل فعل وجد في اللغة على صورة الماضي، ولا يمكن أن تشتق منه

$$
\text { مضارعا أوأمراب' ومنها: }
$$

${ }^{13}$ Alghulayaini . Jami'u al-Durus (Beirut: Daru al-Fikri. 2006) Hal. 55

${ }^{14}$ Ibid. Hal 56

${ }^{15}$ Ibid. Hal 31

${ }^{16}$ Ibid. Hal 55 
- قلّ (بمعنى النفي)، مثلا "قلّ رجل يفعل ذالك" بمعنى ما رجل يفعل

ذالك

كل منها لا يتصرف ولا يتعلق بالزمان.

ب) الفعل الملازم بصيغة المضارع

هو كل فعل لايمكن أن تشتق منه ماضيا أو أمرا، منه:

- أَهَلُّمُ (بمعتى أقبل) هو الفعل الممضارع الجحامد، ودخول همزة المتكلم دليل

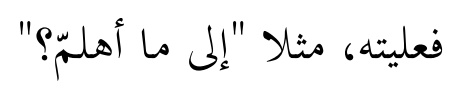

IV " يَهِيْطُ" بمعنى يصيح و يضيح، مثلا "يهيط الفلان "

ج) الفعل المازم بصيغة الأمر

والفعل قد يكون أيضا مخصوصا بصيغة الأمر أو هو كل فعل لايمكن أن تشتق منه ماضيا أو مضارعا، ومن هذه الأفعال:

- هَبْ (بمعنى احسب و افرض) ، مثلا "هب عليا حاضرا". ولم يكن المقصود به فعل الأمر من الفعل "هاب" من الهيبة، لأن وهب متصرف،

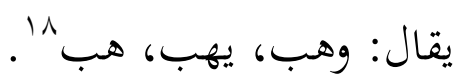
- هأ (بمعنى خذ)، مثلا "هأ حقوقه" - هات (بمعنى أعطيني)، مثلا: "هات طعاما" .

${ }^{18}$ Ibid 
مسروحا وعرفان غزالى

\section{- تعال (بمعنى أقبل)، مثلا "تعال في أي وقت يعجبك"}

- و يمكن عن المناقشة السابقة للفعل المالازم بصورة الواحد تحصيل النتيجة

$$
\begin{aligned}
& \text { على صورة تالية . } \\
& \text { Y. . . صياغ الفعل تقوم مقام الإسم }
\end{aligned}
$$

الفعل هو كلمة من الكلمات الثلاثة الإسم والفعل والحرف. لكل منها وظائف مختلفة ككون الإسم يستعمل للفاعل أو نائبه والمبتدء والخببر والمفعول، وكون الفعل يستعمل للفعل الماضي والفعل المضارع والفعل الأمر، وكون الحرف للرابط. ومع ذلك، إذا درسنا بعمق أكثر، كانت وظيفة الفعل قامت مقام وظيفة الإسم ككون الفعل مبتدءا مثلا "أن تصوم خير لكم" فاللفظ تصوم الفعل المضارع هو مبتدء، أو مفعولا مثلا "احذر أن تأكل في الرمضان" واللفظ تأكل الفعل المضارع وهو مفعولا. يدخل فيه الحرف المصدرية التي تأول الفعل المضارع بالمصدر فبذالك حكم الفعل كحكم الإسم. والحرف المصدرية كلها ثمنية أحرف.

أن الحرف المصدرية كلها ستة وهي أنّ وأن وكي وما المصدرية وما الظرفية ولو.

وزاد الجندي اللام والذي فكلها ثمنية. ‘ُ أب أ. أنّ (الثقيلة)

هي توصل باسمها وخبرها، مثلا "عجبت من أن زيدا قائم" ومنه أية في القرأن "أولم يكفهم أنا أنزلنا عليك الكتاب يتلى عليهم" (العنكبوت: . ه). وأن المخففة كالثقيلة وتوصل باسمها وخبرها لكن اسمها يكون محذوفا واسم المثقلة

$$
\text { مذكورا. }
$$

\footnotetext{
${ }^{19}$ Ibid

${ }^{20}$ Jamaluddin, Ibnu Aqil, Tanpa Tahun (Surabaya: Toha Putra) Hal 22.
} 
هي توصل بالفعل المتصرف ماضيا مثل "عجبت من أن قام زيد" ومضارعا

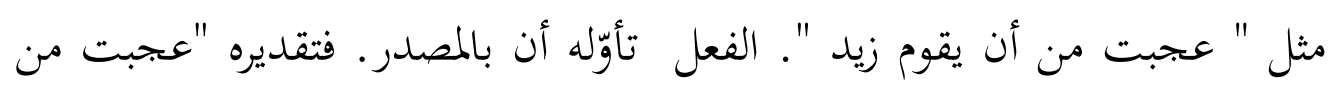

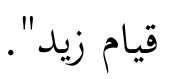

ت. تمي

هي توصل بالفعل المضارع فقط مثل "إجْتَهِذْ لِكَيْ تَنْجَحَ". تنجح هو

الفعل المضارع تأوّله كي بالمصدر. فمصدره "إجتهد لنجاحك". يششترط كونه بعد

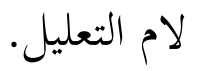

ث.لو غير الشرطية

هي توصل بالفعل الماضي، مثل "وَدَّ أَبُوكَ لَوْ بَحَحْتَ". بنجحت هو الفعل

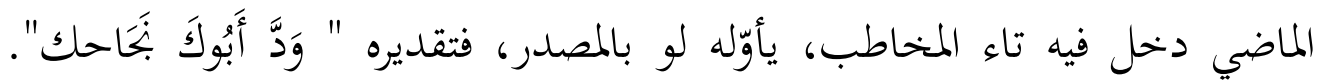

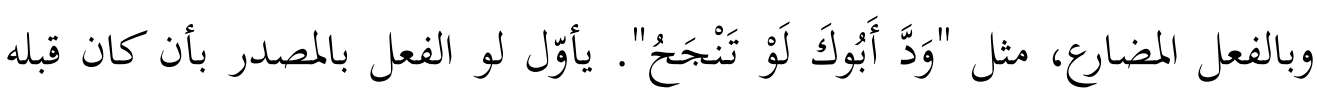
الفعل أي لم يقع في أول الجملة وليس هناك جملة شرطية. ج. ما المصدرية

هي توصل بالفعل الماضي، مثل "أَْْرَنِي مَا سَمِعْتُ عَنْلَّت" سمعت هو الفعل

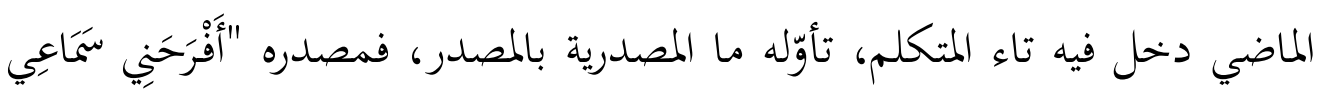

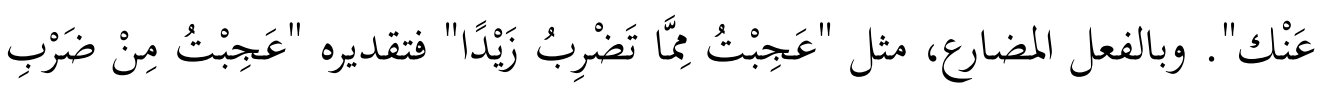

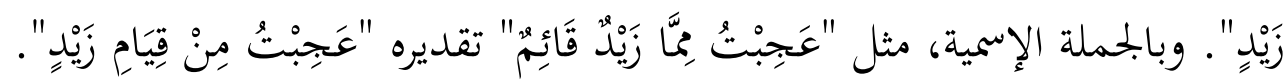
ح. ما الظرفية

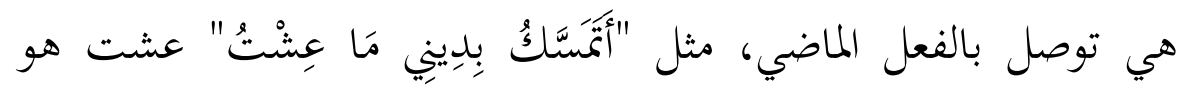
الفعل الماضي دخل فيه تاء المتكلم، تأوّله ما الظرفية بالمصدر، فمصدره "أَتَّسَّكُ

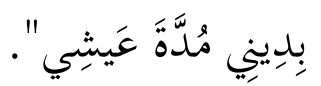
خ الن 
بشرط مدخولها فعلا مضارعا منصوبا بها، و اتصالها بمعمول فعلي

الإرادة كقوله تعالى "ولكن يريد لتطهر كم" (المائدة:7). فتقديره "ولكن يريد تطهيرها كم". و اتصالها بمعمول فعلي الأمر "وأمرنا لنسلم لرب العالمين" (الأنعام: VI) ، تقديره " وأمرنا إسلامنا لرب العالمين".

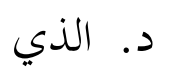

قال بعض النحاة هو يوصل بالفعل، مثلا "وَخُضْتُمْ كَالَّنِي خَاضُوا" (التوبة: 79). خاضوا هو الفعل الماضي دخل فيه ضمير الجمع، يأوّله الذي بالمصدر، فمصدره "وَخُضْتُمْ كَخَوْضِهِمْه" الذي عادة اسم الموصول وفي هذه الأيات هو حرف المصدرية، اذا كان هو اسم الموصول فلابد من لفظ الذين لأن قبله يدل لل

وكل ما تقدم أفعال قامت مقام الإسم لأها إذا دخلت فيها الحرف المصدرية يمكن جعلها المبتداء والخبر والفاعل ونائبه وما سواه ذالك من سائر اللأسماء المرفوعات أو المنصمبات أو المخفوضات. وكل فعل إذا اتصل به حرف المصدرية فهو يؤول بالمصدر أي له حكم المصدر. و يمكن عن المناقشة للحرف المصدرية تؤول بالمصدر تحصيل النتيجة على تلى صورة تالية. r. تحليل أزمان الفعل - مان

أن الزمن جزء من معنى الفعل ولكنه ليس جزءا من معنى الصفة، فالفعل "ضرب" مثلا فيه عنصران: الضرب المستفاد من الإشتقاق والمضي المستفاد من 
الصيغة، فإذا علمنا أن الضرب حدث وأن المضي زمن فقد علمنا أن "ضرب" فعل

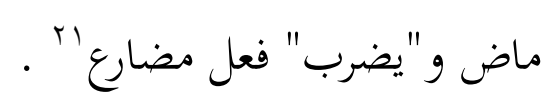

ذكر البيجوري أن لأزمان الفعل في اللغة العربية ثلاثة أنواع الزمن الماضي

والزمن الحاضر والزمن المستقبل، فأما الحاضر والمستقبل فيدل هما الفعل المضارع و الماضي يدله فعل الماضي، والغالب للفعل الماضي زمن ماضي وللمضارع زمن حاضر

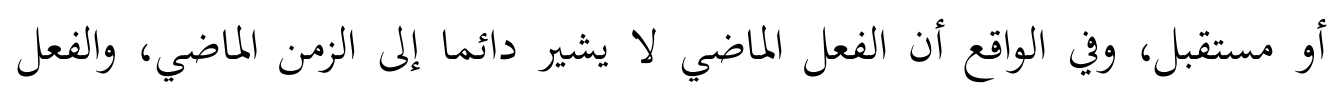
المضارع لا يشير دائما إلى الزمن الحاضر أو المستقبل. كما في أية القرأن "اذا جاء نصر الله" (الفتح: () في هذه الآية هناك الفعل الماضيي اعني "جاء" التي توجد فيها الزمن القادم، في حين أن الأصل القانوني للفعل الماضي يجب عليه أن يدل الزمن الماضي، و اتضح أن هناك عوامل أخرى التي تغير الزمن للفعل الماضي وهي لفظ"اذا" التي قبل دخولما في الفعل الماضي هو يدل للزمن الماضي ثم تغير الزمن

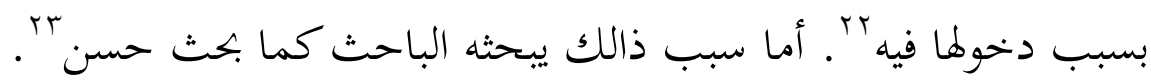
أ. أ. تغير زمن الفعل

إن زمن الفعل قد يتغير بسبب دخول العوامل. فالفعل الماضي قد يشير الى

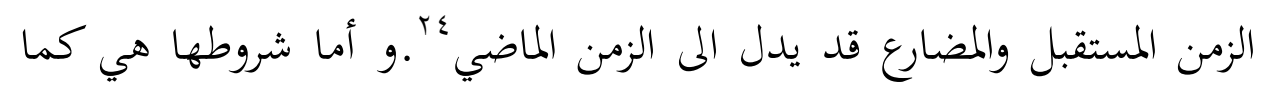
التالي: ب. شروط الزمن الحالي في الفعل الماضي يشير الفعل الماضي على الزمن الحالي بالشروط التالي: - للعقود، مثلا "ووهبتك هذه الفرس".

${ }^{21}$ Tamam Hasan, al-Lughah al-Arobiyah Ma'naha wa Mabnaha, 1998 (Kairo: Alam alKutub) hal. 255

${ }^{22}$ Ahmad Ibnu Muhammad al-Showi Almaliki, Hasyiyah al-Showi 2007 (Beirut: Daru alFikri) Hal 412.

${ }^{23}$ Loc. Cit 


$$
\begin{aligned}
\text { - الأن، مثلا "الأن جئت بالحق (البقرة: V)" المروط الزمن المستقبل في الفعل الماضي }
\end{aligned}
$$

يشير الفعل الماض على زمن الحال بالسبب التالي:

- أن يوقع بعد حرف الشرط غير لو، مثلا "إن استقام التلميذ عفوت عنه

- أن يوقع بعد النفي وقبله حرف القسم، مثلا "تالله لا كلمتك حتى

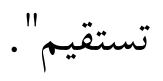

$$
\begin{aligned}
& \text { - للدعاء، مثلا "رحمه الله". }
\end{aligned}
$$

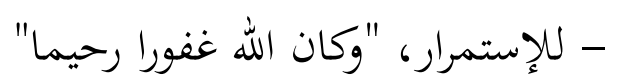

$$
\begin{aligned}
& \text { - للتحضيض، مثلا "هال فعلت بكذا" لهنول } \\
& \text { - للتمني، مثلا، تمنيت أن لو قد حدث كذا" } \\
& \text { - للترجي، مثلا "عسى الله يجملنا مع أصحابنا". } \\
& \text { ث..شروط الزمن الماض في الفعل المضارع } \\
& \text { يشير الفعل المضارع على الزمن الماض اذا دخل عليه: }
\end{aligned}
$$

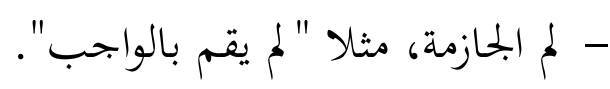

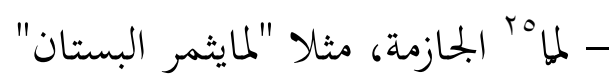

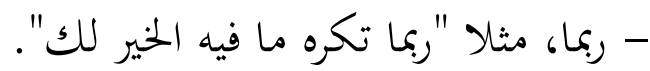

وكل مثال من صيغة الفعل الماضي والمضارع قد يمكنان

دلالتهما على الماضي أو الحال أو الأستقبال بحسب القرينة الظرفية منها أمس ولئه

والأن وغدا، مثلا: أمس ذهبت للمزرعة، الأن جئت بالحق، سنستقبل للأستاذ 
ويمكن عن المناقشة لتغير زمن الفعل تحصيل النتيجة على صورة تالية.

$$
\text { ج. زمن الفعل من معنى الجههة }
$$

الفعل الماضي والمضارع يمكنان ان تدخل فيهما أدوات التي تدل على انلى زماغما لتقوية الزمن فيهما كقد و لقد للفعل الماضي و التنفيس للفعل

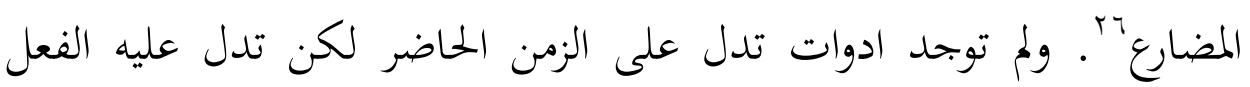

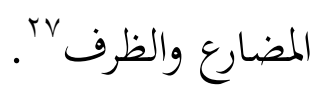

الزمن الماض في "فعل" والحال أو المستقبل في "يفعل" من النظام الصرفي.

ثم بحسب ما يعرض الزمن في هاتين الصيغتين منمعا ني الجهة التي تفصح عنها اصطلاحات البعد والقرب والإنقطاع والإتصال والتجدد والإنتهاء والإستمرار والمقاربة والشروع والعادة والبساطة أي الحاو من معنى الجهة أو بعبارة أخرى عدم الجهة، فيكون معنى الجهة هنا معنى عدميا. أن الأزمنة لا تربط بأوقات محددة، فالسياق والقرائن تصرف الزمن النحوي للتعبير عن الوقت حسب المعنى المختار، مثلا "ذهب محمد قبل خمسة دقائق"، فتحديد زمن ذهاب محمد و قول المتكلم خمسة دقائق. فبدالك قريب الزمن وبعيده لا يربطان بأوقات محددة أي بحسب وقوع حديثه إذا وقع كل اليوم

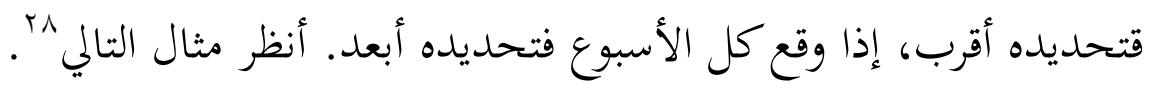

$$
\text { - قد قامت الصالاة - سيتعلم أخي اللغة العربية }
$$

${ }^{26}$ Ibnu Alhasyimi, al-Qowaid al-Asasiyyah li Lughoti al-Arobiyati, 2009 (Beirut: Daru alKutub) Hal.14

${ }^{27}$ Alghulayaini . Jami’u al-Durus (Beirut: Daru al-Fikri. 2006) Hal. 44

28 Muhmmad Arroihani, Ittijahaatu at-Tahlili al-Zamani fi Dirosati al-Lughoti alArobiyati, tanpa tahun (kairo:Daru Qiba) Hal.271 
هذان مثلان يفيدان معنى القريب لكن تحديدهما نختلفان، الثاني قريب هو

$$
\begin{aligned}
& \text { وقع كل اليوم مرة، والأول أقرب هو وقع كل اليوم خمس مرات. } \\
& \text { ح. الجهة الزمن الفعل }
\end{aligned}
$$

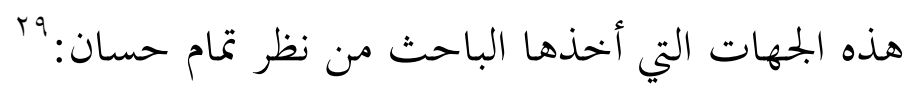

\begin{tabular}{|c|c|c|c|}
\hline الصيغة & الجهة & الزمن & الرقم \\
\hline كان - فعل & البعيد المنقطع & \multirow[t]{3}{*}{ الماض } & 1 \\
\hline كان - قد فعل & القريب المنقطع & & $r$ \\
\hline كان - يفعل & المتجدد & & $\mu$ \\
\hline قد فعل & المنتهي بالحاضر & & $\varepsilon$ \\
\hline ما زال - يفعل & المتصل بالحاضر & & 0 \\
\hline ظله - يفعل & المستمر & & 7 \\
\hline فعل & البسيط & & V \\
\hline كاد - يفعل & المقارب & & $\Lambda$ \\
\hline طفق - يفعل & الشروعي & & 9 \\
\hline
\end{tabular}

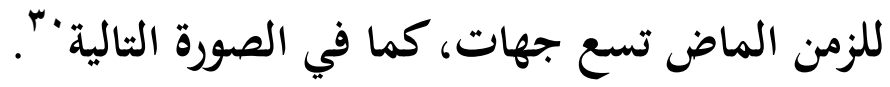

\begin{tabular}{|c|c|c|c|}
\hline الصيغة & الجهة & الزمن & الرقم \\
\hline يفعل & العادي & & 1 \\
\hline
\end{tabular}

وللزمن الحالي ثلاث جهات، كما في الصورة التالية: 'ب

${ }^{29}$ Tamam Hasan, al-Lughah al-Arobiyah Ma'naha wa Mabnaha, 1998 (Kairo: Alam alKutub) hal. 243

${ }^{30}$ Ibid

${ }^{31}$ Ibid. Hal. 244 


\begin{tabular}{|c|c|c|c|}
\hline يفعل & والتجددي & الحالي & $r$ \\
\hline يفعل & والإستمراري & & $\mu$ \\
\hline
\end{tabular}

وللزمن المستقبل أربع جهات، كما في الصورة التالية: بَ

\begin{tabular}{|c|c|c|c|}
\hline الصيغة & الجهة & الزمن & الرقم \\
\hline يفعل & البسيط & \multirow{4}{*}{ المستقبل } & 1 \\
\hline سيفعل & القربي & & $r$ \\
\hline سوف يفعل & البعيد & & $\mu$ \\
\hline سيظل - يفعل & الإستمراري & & $\varepsilon$ \\
\hline
\end{tabular}

الخلاصة

بعد أن قام الباحث بتحليل البيانات في الباب الثاني والثالث، يريد أن يلقي خلاصة هذا البحث تلخيصا واختصارا وتسهيلا للقراءة في فهم ما كتبه وما بحثه، وبحث الباحث في كل من المباحث من توضيح عن صياغ الفعل وزمنه في اللغة العربية. والخلاصة التي يستطيع الباحث أن يقدمها فيما يلي: صيغة الفعل هي تشكيل الفعل في العربية عادة ما يتألف من ما لا يقل عن ثلاثة أحرف أصلية، صياغ الفعل كلها ثلاثة هي الفعل الماضي والفعل المضارع والفعل الأمر وكل منها مقترن بالزمن. و يمكن وقوع صيغة الفعل مقام الإسم بشرط أن يوصل به

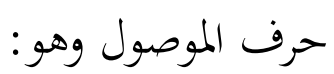

$$
\begin{aligned}
& \text { ( ) أنّ (الثقيلة) } \\
& \text { ب) أن (المصدرية) } \\
& \text { (ب }
\end{aligned}
$$




$$
\begin{aligned}
& \text { ع) لو (غير الشرطية) } \\
& \text { 0) ما (المصدرية) } \\
& \text { 7) ما (الظرفية) } \\
& \text { V) اللام والذي. }
\end{aligned}
$$

الفعل من حيث أداءه معنى لايتعلق بزمان أو يتعلق به قسمان هما جامد ومتصرف. فأماالمتصرف فيمكن أن بجعل كلا من صياغ الأفعال صيغة للفعل الأخر وله زمن. وأما الفعل الجامد فهو ما أشبه الحرف من حيث أداءه معنى بحردا عن الزمن المعتبر في الأفعال فلزم مثله طريقة واحدة في التعبير. لأن للجامد ليس له زمن فعليه صورة واحدة أي لا بجعله صيغة للفعل الأخر كنعم هو الفعل الجامد مخصوص بصيغة الفعل الماضي، ويهيط خخصوص بصيغة الفعل المضارع، وهأ مخصوص بالفعل الأمر. ولأفعال المتصرف لها زمن مختلف، فالفعل الماضي له زمن ماض بأن وقع الجدث قبل الكلام. والفعل المضارع له زمن حال بأن وقع الحدث في وقت الكالام، و مستقبل بأن وقع بعد الكالام. والفعل الأمر له زمن مستقبل كما ذكر في الفعل المضارع، والفرق بينهما أن المضارع خبري، والأمر إنشائي.

الغالب للفعل الماضي زمن ماضي وللمضارع زمن حاضر أو مستقبل، لكن في الواقع أن الفعل الماضي لا يشير دائما إلى زمن ماضي، والفعل المضارع لا يشير دائما إلى زمن حاضر أو مستقبل. كما في أية القرأن "اذا جاء نصر الله" (الفتح: إي ) في هذه الآية هناك الفعل الماضيي اعني "جاء" التي توجد فيها الزمن القادم، في حين أن الأصل القانوني للفعل الماضي يجب عليه أن يدل الزمن الماضي، و اتضح أن هناك عوامل أخرى التي تغير الزمن للفعل الماضي وهي لفظ"اذا" التي قبل دخوها في الفعل الماضي 
هو يدل للزمن الماضي ثم تغير الزمن بسبب دخولها فيه. فبذالك صيغة الفعل الماضي والمضارع قد يمكنان دلالتهما على الزمن الماضي أو الحال أو الإستقبال بحسب القرينة. الفعل الماضي والمضارع يمكنان ان تدخل فيهما أدوات التي تدل على زمنهما لتقوية الزمن فيهما كقد و لقد للفعل الماضي، والتنفيس للفعل المضارع. ولم توجد ادوات تدل على الزمن الحاضر لكن تدل عليه الفعل المضارع والظرف. الزمن الماض في "فعل" والحال أو المستقبل في "يفعل" هو من النظام الصرفي. تم بحسب ما يعرض الزمن في هاتين الصيغتين من معاني الجهة التي تفصح عنها

$$
\text { اصطلاحات كما يلي: للزمن الماضي تسع جهات }
$$

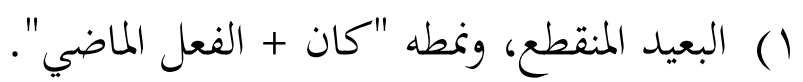$$
\text { r) القريب المنقطع، و نمطه "كان + قد + الفعل الماضي". }
$$$$
\text { ץ) المتجدد، ونمطه "كان + الفعل المضارع". }
$$$$
\text { ع) المنتهي بالحاضر، ونمطه "قد + الفعل الماضي". }
$$$$
\text { ه) المتصل بالحاضر، ونمطه "ما زال + الفعل المضارع". }
$$$$
\text { 7) المستمر، ونمطه "ظلّ + الفعل المضارع". }
$$$$
\text { V البسيط، ونمطه "وزن الفعل الماضي". }
$$$$
\text { ^) المقارب، ونمطه "كاد + يفعل". }
$$

9) الشروعي، ونمطه "طفق + الفعل الماضي".

$$
\text { ولزمن الحالي ثلاث جهات، وهي: العادي، ونمطه "الفعل المضارع". }
$$




$$
\begin{aligned}
& \text { r) التجددي، ونمطه "الفعل المضارع". } \\
& \text { ץ) الإستمراري، ونمطه "الفعل المضارع". } \\
& \text { وللزمن المستقبل أربعة جهات } \\
& \text { () البسيط، ونمطه "الفعل المضارع". } \\
& \text { ب) القريب، ونمطه " س + يفعل". } \\
& \text { r) البعيد، ونمطه "سوف + يفعل". } \\
& \text { ع) الإستمراري، ونمطه "سيظل + يفعل". }
\end{aligned}
$$

والأزمنة لا تربط بأوقات محددة، فالسياق والقرائن تصرف الزمن النحوي للتعبير

عن الوقت حسب المعنى المختار، مثلا "ذهب محمد قبل خمسة دقائق"، فتحديد زمن ذهاب محمد وقول المتكلم خمسة دقائق. الإقتراحات

بعد أن حلل الباحث عن موضوع "تحليل صياغ الفعل وأزمانه في اللغة العربية"،

$$
\text { يريد أن يعطي الاقتراحات. وهي كما يلي: }
$$

إن تعليم القواعد النحوية أو بناء الجملة والصرفية أو مورفولوجي و مورفوسينتاك (Morposintax)

$$
\text { الدراسات اللغوية، سواء كانت عربيا أو غيره. }
$$

ينبغي للمتعلم أن يحلل بين اللغة العربية وغيرها، ليعرف المتعلم أها أخصّ من ريّ

غيرها.

\section{المراجع}

البيجوري, ا. (دون عام). فتح رب البارية. سورابايا: دار العلم. 
الريحاني، م، ع. (دون عام). التحاهات التحليل النمني في الدراسات اللغوية. القاهرة. دار قباء.

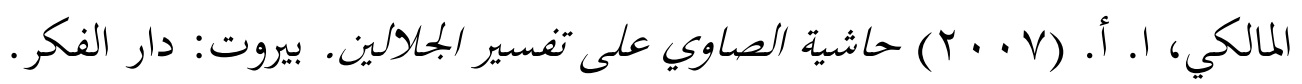
الغلاييني، م. (ך . . ץ). جامع الدروس. بيروت: دار الفكر. عبد البميد. (؟ . . ب). دلالة الزمان في العربية ( دراسة النسق النماني للأفعال): دار توبقال للنشر الهاشمي ، ا. (9 . . ؟ ). القواعد الأساسية للغة العرابي. بيروت: دار الكتب. حمدون، ا. (دون عام). شرح المكودي لألفية ابن مالك. سماراع. طه فوترا

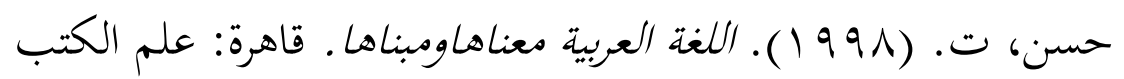
يوسف، طا. (1991) ). المعجم المفصّل في الإعراب. اندونيسيا. حرمين

Chaer, A. (2012). Linguistik Umum. Jakarta: Rineka Cipta.

Mardiah, Z. (2014). Verba Perfektum dan Verba Imperfektum. AL-AZHAR INDONESIA SERI HUMANIORA, 204.

Moleong, L. (2011). Metodologi Penelitian Kualitatif. Bandung: Rosdakarya.

Sugiyono. (2011). Metode Penelitian Kuantitatif dan Kualitatif, dan R\&D. Bandung: Alfabeta.

Verhaar, J. W. (2010). Asas-Asas Linguistik Umum. Yogyakarta: Gadjah Mada University Press.

Zed, M. (204). Metode Penelitian Kepustakaan. Jakarta: Yayasan Obor Indonesia. 